\title{
Intronic TP53 Germline Sequence Variants Modify the Risk in German Breast/Ovarian Cancer Families
}

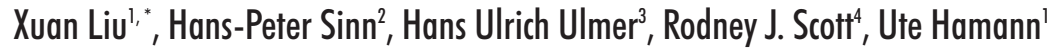 \\ 'Deutsches Krebsforschungszentrum, Division of Molecular Genome Analysis, B055, Im Neuenheimer Feld 580, D-69120 Heidelberg, Germany; *Present address: \\ Hospital of the University for Chinese Medicine, VR-100075 Beiijng, China; 2Department of Pathology, University of Heidelberg, Im Nevenheimer Feld 220, D-69120 \\ Heidelberg; Germany; ${ }^{3}$ Städtisches Klinikum Karlsruhe, D-76133 Karlsruhe, Germany; ${ }^{4}$ Discipline of Medical Genetics, School of Biomedical Sciences, University \\ of Newcastle, Newcastle, Australia
}

Key words: TP53, germline mutations, polymorphisms, familial breast/ovarian cancer

Corresponding author: PD Dr. Ute Hamann, Deutsches Krebsforschungszentrum, Division of Molecular Genome Analysis, B055, Im Neuenheimer Feld 580, D-69120 Heidelberg, tel. +496221 42 2347, fax +496221 424721

e-mail: u.hamann@dkfz-heidelberg.de

Submitted: 21 July 2004

Accepted: 30 July 2004

\begin{abstract}
To establish the contribution of TP53 germline mutations to familial breast/ovarian cancer in Germany we screened the complete coding region of the TP53 gene in a series of German breast/ovarian cancer families negative for mutations in the BRCA1 and BRCA2 genes.

Two different intronic TP53 sequence variants were identified in 6/48 (12.5\%) breast/ovarian cancer families. A novel $A$ to $T$ nucleotide change at position 17708 in intron 10 segregating with the disease was detected in three breast cancer families (6.2\%). One $17708 \mathrm{~A}>\mathrm{T}$-associated breast tumour showed loss of the wild-type allele. This variant was also found in 5/1 12 (4.5\%) healthy controls indicating that it is a polymorphism. A second sequence variant changing a $G$ to $C$ at position 13964 in intron 6 not segregating with the disease was found in two breast cancer families and one breast-ovarian cancer family (6.2\%). This variant has previously been shown to occur at an elevated frequency in hereditary breast cancer patients from North America and to be of functional importance leading to inhibition of apoptosis and prolongation of cell survival after DNA-damage. Screening of 185 consecutive unselected German breast cancer patients revealed the $13964 \mathrm{G}>\mathrm{C}$ variant in four patients (2.2\%). Immunohistochemical analysis of the TP53 protein showed negative immunoreactivity in normal and tumour tissues of one $17708 \mathrm{~A}>\mathrm{T}$ and six $13964 \mathrm{G}>\mathrm{C}$ carriers. TP53 overexpression was detected in the tumour tissue of one sporadic breast cancer patient carrying the $13964 \mathrm{G}>\mathrm{C}$ variant. Our results show that intronic changes of the TP53 gene may act as or be associated with risk modifiers in familial breast cancer.
\end{abstract}

\section{Introduction}

Breast cancer is the most common malignancy and the leading cause of cancer mortality among women worldwide [1]. Approximately 5-10\% of breast and ovarian cancer cases are due to an inherited susceptibility. The majority of these are due to germline mutations in the BRCA1 and BRCA2 genes [2-5]. However, other genes responsible for inherited susceptibility to breast and/or ovarian cancer have been identified, including TP53, PTEN, and ATM [6].

TP53 germline mutations have been found in the majority of families with the Li-Fraumeni syndrome 
(LFS), which is characterized by a large spectrum of different tumour types usually arising at an early age $[7,8]$. Mutations were also found in Li-Fraumeni-like families (LFL) and in about $1 \%$ of breast/ovarian cancer families [9-14].

The majority of TP53 germline mutations are missense mutations that are most often localised to the conserved exons [15]. Since one third of LFS patients do not harbour detectable TP53 exon mutations, other mutations located in intron and promoter sites could exist, which may be important in regulating gene expression. A few intronic TP53 mutations that result in aberrant gene expression have been identified [16, 17]. Recently a specific intronic TP53 13964 G>C germline mutation with functional activity was found at an elevated frequency in North-American hereditary breast cancer patients [18].

In Germany, germline mutations in BRCA 1 and BRCA2 account for about $30 \%$ of hereditary breast/ovarian cancer families [19-23]. As a substantial proportion of German breast/ovarian families are negative for BRCA1 and BRCA2 germline mutations, we screened the complete coding region of the TP53 gene in a series of 48 breast/ovarian cancer families deemed negative for mutations in both genes. Mutation analysis was performed using a combination of single strand conformational polymorphism analysis (SSCP) followed by DNA sequence analysis.

\section{Methods \\ Breast cancer patients}

Hereditary breast cancer patients were identified through an ongoing research family study of hereditary breast and/or ovarian cancer which recruits families from all over Germany. Families containing three or more members affected with breast/ovarian cancer with at least two breast cancer cases diagnosed under the age of 60 and ovarian cancer diagnosed at any age were ascertained through gynaecologists or in response to press publicity in Germany. Each pedigree was extended through an index case and available related family members.

One hundred and eighty-five unselected consecutive breast cancer patients were recruited from the Städtisches Klinikum Karlsruhe between the years 1998 and 1999. All participants gave informed consent prior to donating blood samples. All cancer cases were verified by pathology reports.

Forty-eight German breast and/or ovarian cancer families negative for BRCA1 and BRCA2 germline mutations were included in this study. Forty-three families were described previously [19-22, 24]. Five families not described in the referenced studies were recently identified and analysed for BRCA1 and BRCA2 mutations (U. Hamann, unpublished results) from which one missense change was identified (see below). According to the definitions by Birch et al [25], none of the families fulfilled the definition for LFS or LFL families.

\section{TP53 mutation analysis}

The entire TP53 coding region (Genbank accession number U94788) and the splice junctions were analysed using PCR-based single strand conformation polymorphism analysis (SSCP), followed by DNA sequencing analysis of all unusual conformers. PCR, primer pairs and cycling conditions were as described $[26,27]$. Amplified samples were diluted 1:10 in formamide buffer (98\% formamide, 10 mM EDTA pH 8, $0.05 \%$ bromophenol blue, $0.05 \%$ xylene cyanol), heated to $95^{\circ} \mathrm{C}$ for $5 \mathrm{~min}$. and chilled in ice for $5 \mathrm{~min}$. Three to five $\mu$ l of this mixture were loaded on to $0.6 \times \mathrm{MDE}$ gels (FMC Biochemicals) and run at $6 \mathrm{~W}$ constant power for 7-16 hours in $0.6 \times$ TBE at room temperature. Variant bands were detected by autoradiography. Any sample revealing a variant band on SSCP gels was sequenced on a CEQ 2000 DNA sequencer (Beckman) according to the manufacturers' instructions or on an $A B I$ model 370 automated DNA sequencer (Perkin Elmer). Both forward and reverse strands of genomic DNA were sequenced to confirm the presence of a mutation.

DNA samples from the 185 breast cancer patients unselected for family history were screened for the 13964 G>C mutation in intron 6 by PCR-based Hhal digestion as described [18].

\section{Loss of heterozygosity}

Loss of heterozygosity was assessed by direct DNA sequence analysis of tumour DNA for the presence or absence of the wild-type allele. A normal control and the constitutional DNA from the same person were analysed on the same gel using identical chemistry.

\section{Immunohistochemistry of archival normal and tumour tissues}

Expression of TP53 was assessed using the DO-7 antibody (DAKO, Copenhagen) on paraffin-embedded normal and tumour tissues. A matching hematoxylin and eosin $(\mathrm{H}+\mathrm{E})$ stained slide was used to determine which parts of the sections were tumour tissue. Two independent stains were done for every case. The percentage of TP53 positive tumour nuclei was determined, overexpression of the TP53 protein was considered to be present if more than $15 \%$ of tumour 
nuclei at the invasion front were stained. Details of the immunohistochemistry analysis and the evaluation procedure are as described previously [28].

\section{Statistical analysis}

(2x2) tables were analysed using two-sided Fisher's exact test. Continuous variables were compared using the Wilcoxon rank-sum test. Two-sided $p$ values of 0.05 or less were considered significant. All results were calculated using S-Plus 4.5 for Windows (Mathsoft Inc., Seattle, USA).

\section{Results}

\section{Intronic TP53 germline mutations in German breast/ovarian cancer families}

Fifty-one probands from 41 breast cancer families and 7 breast-ovarian cancer families were studied for germline mutations of the TP53 gene. Two different intronic TP53 sequence variants were identified in five breast cancer families and one breast-ovarian cancer family (6/48, 12.5\%). These included a novel 17708 $A>T$ variant in intron 10 and a previously reported 13964 G>C variant in intron 6 [29]. Screening of all coding exons of the TP53 gene did not reveal the presence of additional mutations in any of the analysed families. The characteristics of the families carrying these variants are shown in Table 1.

The $13964 \mathrm{G}>\mathrm{C}$ variant in intron 6 was identified in families 19, 26, and P328. All carriers were heterozygous for this mutation. In kindred 19, four females, of whom three were diagnosed with breast cancer at 45,45 , and
49 years of age, respectively, and one with cancer of the fallopian tube at 49 years of age, harboured the variant. In kindred 26, four women carried the variant. Among these, one woman was diagnosed with Hodgkin's disease and breast cancer at 22 and 34 years of age, respectively, and one with breast cancer at 36 years of age. The variant was inherited from the unaffected mother. One aunt of the index patient, 60 years of age, harboured the variant, whereas another one diagnosed with breast cancer at 44 years of age did not. In kindred P328, one woman diagnosed with breast cancer at 51 years of age carried the variant, whereas one aunt on the paternal side diagnosed with breast cancer at 67 years of age, was negative. In addition to the TP53 sequence variant, family P328 also harboured the Tyr179Cys missense mutation in exon 8 of the BRCA 1 gene. Both women affected by breast cancer harboured the BRCA1 missense mutation. One female mutation carrier, 43 years of age, was asymptomatic. The BRCA1 missense mutation was not found in 140 control individuals indicating that it is disease-causative.

A novel 17708 A $>$ T nucleotide change in intron 10 segregating with the disease was detected in breast cancer families 89, 128 and P313. In family 89, four variant carriers were identified, three by direct analysis and one was shown to be an obligatory carrier. The obligatory carrier was diagnosed with cervical cancer at an unknown age and breast cancer at 40 years of age. This patient's mutation was present in both of her daughters, one being diagnosed with breast cancer at 45 years of age and the other is currently unaffected at the age of 40. Two aunts of the index patient were also diagnosed with breast cancer, one being diagnosed with breast cancer at the age of 49 , and the other diagnosed with breast cancer at 70 years of age but

Table 1. Characteristics and TP53 sequence variants in German breast/ovarian cancer families

\begin{tabular}{lccll}
\hline Family & $\begin{array}{c}\text { No. of breast cancers } \\
\text { (age at diagnosis) }\end{array}$ & $\begin{array}{c}\text { No. } \\
\text { of ovarian } \\
\text { cancers }\end{array}$ & Other cancers (age at diagnosis) & TP53 mutation \\
\hline 19 & $6(38,39,45,45,49,50)$ & 2 & Lung $(<45), 2 x$ liver, vulva, colon (39), fallopian tube (49) & IVS6, 13964 G>C \\
\hline 26 & $3(34,36,44)$ & 0 & Hodgkin's disease (22) & IVS6, 13964 G>C \\
\hline P328 & $3(34,51,67)$ & 0 & $5 x$ prostate $(52,59,70,75,<84)$, skin (43) & IVS6, 13964 G>C \\
\hline 89 & $5(40,45,48,51,70)$ & 0 & Cervix, colon, cancer of unknown type & IVS10, 17708 A>T \\
\hline 128 & $5(30,45,52,53,64)^{b}$ & 0 & Brain, stomach/lung & IVS10, 17708 A>T \\
\hline P313 & $3(43,47)^{c}$ & 0 & Malignant melanoma (51), sarcoma (61) & IVS10, 17708 A>T \\
\hline $\begin{array}{l}\text { a Family P328 also carries a Tyr179Cys missense mutation of the BRCAl gene. This mutation was described 35 times previously to the BIC database (39). } \\
\text { b Including a male breast cancer. } \\
\text { c One patient's age at diagnosis is unknown. }\end{array}$ & & \\
\hline
\end{tabular}


Table 2. Clinical, pathological and molecular parameters of breast tumours in $13964 \mathrm{G}>\mathrm{C}$ carriers

\begin{tabular}{|c|c|c|c|c|}
\hline Patients & $\begin{array}{l}\text { Age at diagnosis } \\
\text { of breast cancer }\end{array}$ & Histology $^{a}$ & $\begin{array}{l}\text { UICC }{ }^{b} \text { stage, grade } \\
\text { of malignancy }\end{array}$ & $\begin{array}{l}\% \text { of TP53 positively stained cell nuclei } \\
\text { Tumour tissue/Normal tissue }\end{array}$ \\
\hline \multicolumn{5}{|l|}{ Sporadic } \\
\hline R670 & 63 & IDC & IIIA, G3 & $100 / 0$ \\
\hline R688 & 68 & IDC & I, G3 & $0 / 0$ \\
\hline R728 & 59 & IDC & I, G3 & $0 / 0$ \\
\hline R729 & 50 & IDC & IIA, G3 & $0 / 0$ \\
\hline \multicolumn{5}{|l|}{ Familial } \\
\hline 26/III: 1 & 34 & IDC & I, G2 & not available \\
\hline 26/III: 2 & 36 & IDC & IIB, G3 & $0 / 0$ \\
\hline P328/II: 5 & 67 & IDC & I, G3 & $0 / 0$ \\
\hline P328/III: 5 & 51 & IDC+ILC & IIB, G2 & $0 / 0$ \\
\hline \multicolumn{5}{|c|}{$\begin{array}{l}\text { a IDC = invasive ductal carcinoma, ILC = invasive lobular carcinoma. } \\
\text { b According to UICC (1997) [40]. }\end{array}$} \\
\hline
\end{tabular}
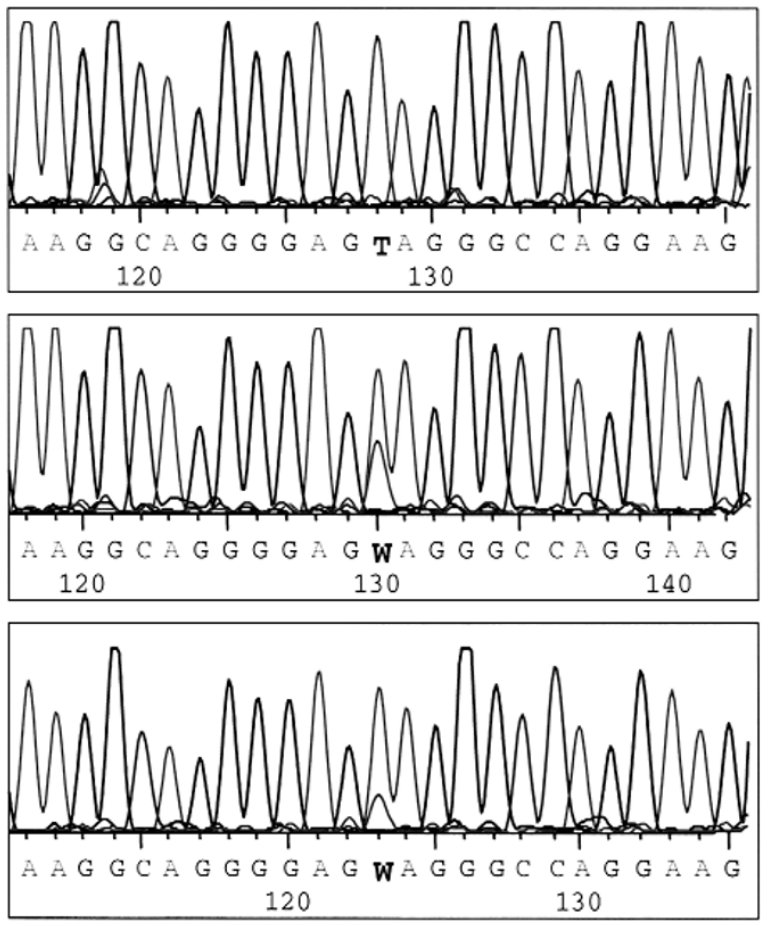

Fig. 1. Electropherograms showing the sequence of the reverse strand of part of intron 10 with the $17708 \mathrm{~A}$ to $\mathrm{T}$ nucleotide change. Top panel: constitutional DNA of a healthy control individual; middle panel: constitutional DNA of breast cancer patient P313; bottom panel: tumour DNA of patient P313 was negative for this variant. In family 128, three female carriers, diagnosed with breast cancer at 30,52, and 53 years of age were identified, two by direct analysis and the third was shown to be an obligatory carrier. This sequence variant was also detected in 5/112 $(4.5 \%)$ healthy controls suggesting that it is a polymorphism rather than a causative mutation.

Tumour DNA which was available from the index patient was analysed for loss of heterozygosity $(\mathrm{LOH})$ at TP53 using direct DNA sequencing analysis. DNA was available from one $17708 \mathrm{~A}>\mathrm{T}$-associated breast tumour from one patient of family P313. In this family two females were diagnosed with breast cancer at 43 and 47 years of age, one male presented with a malignant melanoma at 51 years of age and one male with a sarcoma at 61 years of age (data not shown). The tumour DNA showed loss of the wild-type TP53 allele (Figure 1).

Immunohistochemical analysis revealed a loss of TP53 protein immunoreactivity in normal and tumour tissues.

\section{Association of the $13964 \mathrm{G}>$ C mutation with sporadic breast cancer}

To analyse whether the $13964 \mathrm{G}>\mathrm{C}$ variant is also associated with sporadic breast cancer, 185 unselected 
consecutive German breast cancer patients were screened. Four sporadic breast cancer patients (2.2\%) were determined to harbour the 13964 G>C change compared to three out of 48 (6.2\%) hereditary breast cancer patients ( $p=0.15$; Fisher's exact test). All sporadic breast cancer patients carrying the variant had a negative family history of breast and ovarian cancer as ascertained by medical records and anamnestic questioning. Two variant carriers had a positive family history of other cancers, in one family a kidney cancer occurred at 65 years of age and in the other family two colon cancers and an oesophagus cancer occurred at the ages of 37,61 and 35 , respectively.

\section{Clinical and pathological characteristics of 13964 G > C-associated breast tumours and TP53 expression}

The clinical and pathological features of breast tumours diagnosed in eight $13964 \mathrm{G}>\mathrm{C}$ variant carriers are listed in Table 2. The median age of breast cancer diagnosis was 43.5 years for the four hereditary cases and 61 years for the four sporadic cases. This difference was not statistically significant $(p=0.34$, Wilcoxon rank sum test). Seven patients presented with invasive ductal carcinoma (IDC) of high or intermediate grade of malignancy, and one patient with IDC and invasive lobular carcinoma (ILC) of grade 2 .

Immunohistochemical analysis of TP53 protein expression displayed negative immunoreactivity in normal and tumour tissues of three sporadic and three hereditary breast cancer patients harbouring the 13964 $\mathrm{G}>\mathrm{C}$ variant. Positive staining was detected in the tumour tissue of one sporadic mutation carrier, whereas the normal tissue stained negatively.

\section{Discussion}

In this study we screened the complete coding region of the TP53 gene in 48 German breast/ovarian cancer families negative for mutations in the BRCA7 and BRCA2 genes. Using SSCP and DNA sequencing analysis two different TP53 sequence variants, an A to T nucleotide change at position 17708 in intron 10 and a $G$ to $C$ nucleotide change at position 13964 in intron 6 were identified in five breast cancer families and in one breast-ovarian cancer family.

The $17708 \mathrm{~A}>$ T nucleotide change is novel and has not previously been identified in other populations. Cosegregation of this variant in families 89 and 128, loss of the wild-type allele in a $17708 \mathrm{~A}>$ T-associated breast tumour and the presence of the variant allele in healthy controls suggest that this variant is a polymorphism that may modify breast cancer risk. The negative TP53 protein immunoreactivity displayed by this tumour suggests that mechanisms other than those leading to protein accumulation are involved in the inactivation of TP53 function. These results are consistent with those of Siögren et al, who showed that $33 \%$ of breast tumours with TP53 mutations identified by complementary DNA sequencing did not show positive immunoreactivity [30].

Three German breast/ovarian cancer families harboured the $13964 \mathrm{G}>\mathrm{C}$ variant in intron 6. This variant has previously been reported by several investigators. It has been identified in three out of 73 patients with both breast and ovarian cancers [29]. Due to the lack of functional tests for TP53 protein activity, it has been classified as a non functional polymorphism. It was also detected in five out of 70 children with possible radiation-induced thyroid tumours and in one out of 30 healthy children from areas in Belarus [31]. Since the family history of those patients was not available, no conclusion about an association of this nucleotide change with inherited cancer predisposition was possible. Recently, the 13964 G>C variant was detected at an elevated frequency in familial breast cancer patients from North America [18]. Using immortalised lymphoblastoid cell lines derived from $13964 \mathrm{G}>\mathrm{C}$ variant carriers, the investigators showed that the mutation is functionally active and results in an inhibition of apoptosis and prolongation of cell survival in vitro upon DNA damage in response to cisplatin, suggesting that this mutation affects breast cancer risk. However, strict segregation of this variant with the disease has not been shown.

The frequency of $13964 \mathrm{G}>\mathrm{C}$ variants in our study was $6.2 \%$. This frequency is similar to those previously reported in familial breast cancer patients from Australia [32], North America [18], and Poland [33] being 4.2\%, $7.1 \%$, and $10.7 \%$, respectively. In contrast to the American study in which no association of this variant with sporadic disease was detected, we also identified this variant in $2.2 \%$ of sporadic breast cancer patients from Germany. This frequency is similar to that observed in sporadic breast cancer patients from Australia which was 3.5\% [32]. The discrepancy of these results may partially be explained by differences in the populations.

The $13964 \mathrm{G}>\mathrm{C}$ variant did not segregate with the disease in families 26 and P328 and hence may be not disease-causative. The additional presence of the commonly reported BRCAl missense mutation Tyr179Cys in the same family that segregated with the disease and the absence of this mutation in healthy control individuals suggest that the BRCA 7 mutation may be causative, whereas the TP53 variant is more likely to act as a risk modifier. 
In contrast to the report by Lehman (2000) showing positive TP53 staining in all three 13964 G>C-associated hereditary breast tumours [18], in our study six of the seven 13964 G > C-associated breast cancers did not stain for TP53, and only one sporadic tumour stained positively. These findings suggest that the $13964 \mathrm{G}>C$ variant does not appear to play a direct role in the stabilisation of the TP53 wild-type protein resulting in its abnormal accumulation. The mechanism by which this variant influences breast cancer risk remains to be determined.

Several other germline mutations in intron 6 have been described. A $13961 \mathrm{G}>\mathrm{A}$ sequence variant was identified in six affected members of a Li-Fraumeni family, and in only one out of 184 healthy controls [34]. Strong TP53 protein immunoreactivity was detected in both normal and tumour tissues from all patients. A base substitution of $G$ by $A$ in the $M s p /$ site followed by an insertion of TG was identified in a Li-Fraumeni family and not in 85 healthy controls [35]. Whereas strong TP53 protein immunoreactivity was detected in both normal and tumour tissues from these patients, no aberrant mRNA expression was detected. Further, various other mutations in the region 13487-13494 were reported [36, 37]. Taken together these studies imply that intron 6 of the TP53 gene could be a mutation hot spot. These nucleotide changes may act via novel mechanisms of gene regulation that appear to be important for tumour formation. The presence of $\mathrm{CpG}$-rich Alu repetitive element adjacent to the $13964 \mathrm{G}>\mathrm{C}$ base change may explain the frequency of the sequence variant at this site [38].

The identification of intronic sequence differences that do not directly result in either an abnormal accumulation of TP53 or loss of TP53 activity does not rule out the possibility that one or both of these changes influence disease development. The penetrance of these changes may be low such that in family studies the actual contribution of these changes may be modest but if studied at the population level disease associations may be more apparent. The identification of these changes therefore warrants a population-based study to assess the likelihood that both changes may be low risk modifiers rather than overt causative changes.

In conclusion, the identification of intronic changes in the TP53 gene suggests that there is a relationship between the presence of these changes and disease risk. Overtly, no apparent change in protein function can be determined from these changes suggesting that more subtle affects are more likely to result in an increased disease risk.

\section{Acknowledgements}

We are grateful to all family members and breast cancer patients for their participation in this study. We thank Hartmut Frenzel for a contribution of normal tissues, tumour tissues and clinical data, Anna Jakubowska for critical reading of the manuscript, and Antje Seidel-Renkert, Michaela Schleicher and Michael Gilbert for expert technical assistance. This work was in part supported by the Tumorzentrum Heidelberg/Mannheim D. 10029190.

\section{References}

1. Parkin DM, Pisani $P$ and Ferlay J. Estimates of the worldwide incidence of 25 major cancers in 1990. Int J Cancer 1999; 80: 827-841

2. Ford D, Easton DF, Stratton M, Narod S, Goldgar D, Devilee P, Bishop DT, Weber B, Lenoir G, Chang-Claude J, Sobol H, Teare MD, Struewing J, Arason A, Scherneck S, Peto J, Rebbeck TR, Tonin P, Neuhausen S, Barkardottir R, Eyfjord J, Lynch H, Ponder BA, Gayther SA and Zelada-Hedman M. Genetic heterogeneity and penetrance analysis of the BRCA1 and BRCA2 genes in breast cancer families. The Breast Cancer Linkage Consortium. Am J Hum Genet 1998; 62: 676-689.

3. Miki Y, Swensen J, Shattuck-Eidens D, Futreal PA, Harshman K, Tavtigian S, Liu Q, Cochran C, Bennett LM and Ding W. A strong candidate for the breast and ovarian cancer susceptibility gene BRCA1. Science 1994; 266: 66-71.

4. Wooster R, Neuhausen SL, Mangion J, Quirk Y, Ford D, Collins N, Nguyen K, Seal S, Tran T and Averill D. Localization of a breast cancer susceptibility gene, BRCA2, to chromosome 13q12-13. Science 1994; 265: 2088-2090.

5. Wooster R, Bignell G, Lancaster J, Swift S, Seal S, Mangion J, Collins N, Gregory S, Gumbs C and Micklem G. Identification of the breast cancer susceptibility gene BRCA2. Nature 1995; 378: 789-792.

6. Easton DF. How many more breast cancer predisposition genes are there? Breast Cancer Res 1999; 1: 14-17.

7. Malkin D, Li FP, Strong LC, Fraumeni JF, Jr., Nelson CE, Kim DH, Kassel J, Gryka MA, Bischoff FZ and Tainsky MA. Germ line p53 mutations in a familial syndrome of breast cancer, sarcomas, and other neoplasms. Science 1990; 250: 1233-1238.

8. Srivastava S, Zou ZQ, Pirollo K, Blattner W and Chang EH. Germ-line transmission of a mutated p53 gene in a cancer-prone family with Li-Fraumeni syndrome. Nature 1990; 348: 747-749.

9. Borresen AL, Andersen TI, Garber J, Barbier-Piraux N, Thorlacius S, Eyfjord J, Ottestad L, Smith-Sorensen B, Hovig E and Malkin D. Screening for germ line TP53 mutations in breast cancer patients. Cancer Res 1992; 52: 3234-3236.

10. Cornelis RS, van Vliet $M$, van de Vijver MJ, Vasen HF, Voute PA, Top B, Khan PM, Devilee P and Cornelisse CJ. Three germline mutations in the TP53 gene. Hum Mutat 1997; 9: 157-163.

11. Jolly KW, Malkin D, Douglass EC, Brown TF, Sinclair AE and Look AT. Splice-site mutation of the $\mathrm{p} 53$ gene in a family with hereditary breast-ovarian cancer. Oncogene 1994; 9: 97-102.

12. Prosser J, Porter D, Coles C, Condie A, Thompson AM, Chetty U, Steel CM and Evans HJ. Constitutional p53 mutation in a non-Li-Fraumeni cancer family. Br J Cancer 1992; 65: 527-528.

13. Sidransky D and Messing E. Molecular genetics and biochemical mechanisms in bladder cancer. Oncogenes, tumor suppressor genes, and growth factors. Urol Clin North Am 1992; 19: 629-639.

14. Sun XF, Johannsson O, Hakansson S, Sellberg G, Nordenskiold $\mathrm{B}$, Olsson $\mathrm{H}$ and Borg $\mathrm{A}$. A novel p53 germline alteration identified in a late onset breast cancer kindred. Oncogene 1996; 13: 407-411. 
15. Varley JM, Evans DG and Birch JM. Li-Fraumeni syndrome a molecular and clinical review. Br J Cancer 1997; 76: 1-14.

16. Lozano $G$ and Levine AJ. Tissue-specific expression of p53 in transgenic mice is regulated by intron sequences. Mol Carcinogen 1991; 4: 3-9.

17. Varley JM, Chapman P, McGown G, Thorncroft M, White GR, Greaves MJ, Scott D, Spreadborough A, Tricker KJ, Birch JM, Evans DG, Reddel R, Camplejohn RS, Burn J and Boyle JM. Genetic and functional studies of a germline TP53 splicing mutation in a Li-Fraumeni-like family. Oncogene 1998; 16: 3291-3298.

18. Lehman TA, Haffty BG, Carbone CJ, Bishop LR, Gumbs AA, Krishnan S, Shields PG, Modali R and Turner BC. Elevated frequency and functional activity of a specific germ-line p53 intron mutation in familial breast cancer. Cancer Res 2000; 60: 1062-1069.

19. Hamann U, Haner M, Stosiek U, Bastert G and Scott RJ. Low frequency of BRCAl germline mutations in 45 German breast/ovarian cancer families. J Med Genet 1997; 34: 884-888.

20. Hamann U, Brauch H, Garvin AM, Bastert G and Scott RJ. German family study on hereditary breast and/or ovarian cancer: germline mutation analysis of the BRCAl gene. Genes Chromosomes Cancer 1997; 18: 126-132.

21. Hamann $U$ and Sinn HP. Survival and tumor characteristics of German hereditary breast cancer patients. Breast Cancer Res Treat 2000; 59: 185-192.

22. Hamann U, Liu X, Lange S, Ulmer HU, Benner A and Scott RJ. Contribution of BRCA2 germline mutations to hereditary breast/ovarian cancer in Germany. J Med Genet 2002; 39: E12.

23. Jandrig B, Grade K, Seitz S, Waindzoch B, Muller M, Bender E, Nothnagel A, Rohde K, Schlag PM, Kath R, Hoffken K and Scherneck S. BRCA1 mutations in German breast-cancer families. Int J Cancer 1996; 68: 188-192.

24. Hamann U, Becher H, Zimmermann T, Pella K, Bastert G and Chang-Claude J. German family study on hereditary breastovarian cancer. J Med Genet 1996; 33: 633-635.

25. Birch JM, Hartley AL, Tricker KJ, Prosser J, Condie A, Kelsey AM, Harris $\mathrm{M}$, Jones $\mathrm{PH}$, Binchy $\mathrm{A}$ and Crowther D. Prevalence and diversity of constitutional mutations in the p53 gene among 21 Li-Fraumeni families. Cancer Res 1994; 54: 1298-1304.

26. Varley JM, McGown G, Thorncroft M, James LA, Margison GP, Forster G, Evans DG, Harris M, Kelsey AM and Birch JM. Are there low-penetrance TP53 Alleles? Evidence from childhood adrenocortical tumors. Am J Hum Genet 1999; 65: 995-1006.

27. Evans SC, Mims B, McMasters KM, Foster CJ, deAndrade M, Amos $\mathrm{Cl}$, Strong LC and Lozano G. Exclusion of a p53 germline mutation in a classic Li-Fraumeni syndrome family. Hum Genet 1998; 102: 681-686.

28. Emig R, Magener A, Ehemann V, Meyer A, Stilgenbauer F, Volkmann $M$, Wallwiener D and Sinn HP. Aberrant cytoplasmic expression of the p16 protein in breast cancer is associated with accelerated tumour proliferation. Br J Cancer 1998; 78: 1661-1668.

29. Buller RE, Skilling JS, Kaliszewski S, Niemann T and Anderson B. Absence of significant germ line p53 mutations in ovarian cancer patients. Gynecol Oncol 1995; 58: 368-374.

30. Siogren S, Inganas M, Norberg T, Lindgren A, Nordgren H, Holmberg $L$ and Bergh J. The p53 gene in breast cancer: prognostic value of complementary DNA sequencing versus immunohistochemistry. J Natl Cancer Inst 1996; 88: 173-182.

31. Hillebrandt S, Streffer C, Demidchik EP, Biko J and Reiners C. Polymorphisms in the p53 gene in thyroid tumours and blood samples of children from areas in Belarus. Mutat Res 1997; 381: 201-207.

32. Marsh A, Spurdle AB, Turner BC, Fereday S, Thorne H, Pupo GM, Mann GJ, Hopper JL, Sambrook JF and Chenevix-Trench $\mathrm{G}$. The intronic G13964C variant in p53 is not a high-risk mutation in familial breast cancer in Australia. Breast Cancer Res 2001; 3: 346-349.

33. Fiszer-Maliszewska L, Kazanowska B, Kusnierczyk P, Manczak M, Niepieklo W, Pochron-Zeman B and Nowakowska B. Is p53 intronic variant $\mathrm{G} 13964 \mathrm{C}$ associated with predisposition to cancer? J Appl Genet 2003; 44: 547-552.

34. Avigad S, Barel D, Blau O, Malka A, Zoldan M, Mor C, Fogel M, Cohen IJ, Stark B, Goshen Y, Stein J and Zaizov R. A novel germ line p53 mutation in intron 6 in diverse childhood malignancies. Oncogene 1997; 14: 1541-1545.

35. Barel D, Avigad S, Mor C, Fogel M, Cohen IJ and Zaizov R. A novel germ-line mutation in the noncoding region of the $p 53$ gene in a Li-Fraumeni family. Cancer Genet Cytogenet 1998; 103: 1-6.

36. McDaniel T, Carbone D, Takahashi T, Chumakov P, Chang EH, Pirollo KF, Yin J, Huang $Y$ and Meltzer SJ. The Mspl polymorphism in intron 6 of p53 (TP53) detected by digestion of PCR products. Nucleic Acids Res 1991; 19: 4796.

37. Peller S, Kopilova Y, Slutzki S, Halevy A, Kvitko K and Rotter V. A novel polymorphism in intron 6 of the human p53 gene: a possible association with cancer predisposition and susceptibility. DNA Cell Biol 1995; 14: 983-990.

38. Magewu AN and Jones PA. Ubiquitous and tenacious methylation of the $\mathrm{CpG}$ site in codon 248 of the $\mathrm{p} 53$ gene may explain its frequent appearance as a mutational hot spot in human cancer. Mol Cell Biol 1994; 14: 4225-4232.

39. Breast Cancer Information Core (BIC) database [http: //www. nhgri. nih. gov/Intramural_research/Lab_transfer/Bic/]. 2004.

40. UICC (1997) TNM classification of malignant tumours. 5th edn. Sobin LH, Wittekind Ch (eds.). Wiley \& Sons, New York. 